\title{
Trends in Computer-Aided Manufacturing in Prosthodontics: A Review of the Available Streams
}

\author{
Jaafar Abduo, ${ }^{1,2}$ Karl Lyons, ${ }^{3}$ and Mohammed Bennamoun ${ }^{2}$ \\ ${ }^{1}$ School of Dentistry, Melbourne University, 720 Swanston Street, Carlton, Melbourne, VIC, 3010, Australia \\ ${ }^{2}$ School of Computer Science and Software Engineering, University of Western Australia, 35 Stirling Highway, Crawley, \\ WA 6009, Australia \\ ${ }^{3}$ Department of Oral Rehabilitation, Faculty of Dentistry, University of Otago, 310 Great King Street, Dunedin 9054, New Zealand
}

Correspondence should be addressed to Jaafar Abduo; jaafar_abduo@hotmail.com

Received 29 November 2013; Accepted 10 March 2014; Published 8 April 2014

Academic Editor: Michael E. Razzoog

Copyright (C) 2014 Jaafar Abduo et al. This is an open access article distributed under the Creative Commons Attribution License, which permits unrestricted use, distribution, and reproduction in any medium, provided the original work is properly cited.

\begin{abstract}
In prosthodontics, conventional methods of fabrication of oral and facial prostheses have been considered the gold standard for many years. The development of computer-aided manufacturing and the medical application of this industrial technology have provided an alternative way of fabricating oral and facial prostheses. This narrative review aims to evaluate the different streams of computer-aided manufacturing in prosthodontics. To date, there are two streams: the subtractive and the additive approaches. The differences reside in the processing protocols, materials used, and their respective accuracy. In general, there is a tendency for the subtractive method to provide more homogeneous objects with acceptable accuracy that may be more suitable for the production of intraoral prostheses where high occlusal forces are anticipated. Additive manufacturing methods have the ability to produce large workpieces with significant surface variation and competitive accuracy. Such advantages make them ideal for the fabrication of facial prostheses.
\end{abstract}

\section{Introduction}

Prosthodontics is defined as the dental specialty pertaining to the diagnosis, treatment planning, rehabilitation, and maintenance of the oral function, comfort, appearance, and health of patients with clinical conditions associated with missing or deficient teeth and/or maxillofacial tissues using a biocompatible substitute [1], which is most commonly a prosthesis. In order for prosthesis to fulfill its function, it should be durable, aesthetic, accurate, and comfortable. These requirements should be accomplished by any prosthesis fabrication method.

Conventional fabrication methods involve recording an impression of the treatment site, pouring a stone model and constructing a wax pattern. The wax pattern is invested and replaced with a permanent material such as metal, ceramic, acrylic, or silicone. Such steps require considerable human intervention and manipulation of materials that may also exhibit inherent processing shrinkage and/or expansion [2, 3]. This can translate to increased processing errors and inaccuracies, as well as increased time and cost. Further, considerable skill is required to produce a prosthesis of good quality. The problems of the conventional protocol are however offset by the familiarity of the processes by the operators.

The limitations of the conventional fabrication method can be more obvious with prostheses that are fabricated less than commonly, such as facial prostheses that require a shade and features that match the remaining tissues [4-6]. Silicone facial prostheses fabricated using the conventional protocol also exhibit limited longevity from an aesthetic perspective because they are likely to tear at the thin margins and degrade on the external surface [7]. In general, the longevity of a facial prosthesis has been reported to be in the range of 612 months $[8,9]$. To overcome this limitation, fabrication of multiple prostheses in one treatment episode has been advocated $[4,5]$. Furthermore, due to the complexity of prosthesis construction and the limited expertise in specialist centers, patients tend to be deprived of adequate prosthetic treatment [10]. Reducing the reliance on the human variable and implementation automated design and fabrication techniques would therefore facilitate the production of more reliable prostheses. 
Computer-aided design and computer-aided manufacturing (CAD/CAM) have revolutionized dentistry. With the continuous development of computerized engineering technology, digitized medical treatment modalities are becoming an integral approach for prosthodontics, orthodontics, and oral and maxillofacial surgery. This paper will review the existing computer-aided manufacturing streams for oral and maxillofacial prosthodontic treatment.

\section{Digital Prosthodontic Treatments}

As with any new technology, the utilization of computeraided manufacturing in prosthodontics was not without impediments. Historically, the early application was crude and associated with compromised quality and precision of the prosthesis [11, 12]. Positively, the more recent literature reflects a tendency for continuous improvements of computer-aided manufacturing streams and a gradual shift towards wider acceptance of the new technology as a mainstream for prosthesis fabrication. From the practical perspective, the minimal requirement of computer-aided manufacturing is provision of a prosthesis that is, at least, equivalent to the one produced by conventional fabrication methods.

To date, the exponential increase in the application of computer-aided manufacturing in prosthodontics is attributed to continuous systems development and refinement, greater ability for quality control, parallel material development, and the possibility of virtual evaluation. Other areas of refinement include scanning technology, modelling software, and production systems, and the systems are becoming more user friendly [11, 12]. The development of quality control, production precision, and a simpler fabrication protocol by industry has tempted the medical profession to adopt and modify these technologies [11, 13-16]. In comparison to the conventional fabrication methods, computeraided manufacturing has the advantage of omitting multiple error-introducing steps such as impression, waxing, and casting $[11,12,17]$. This is assumed to reduce the error sources and increase the precision of the prosthesis. Furthermore, since modelling and production are automated procedures, there is an overall reduction of fabrication time and cost.

Alongside computer-aided systems development, new materials have emerged for prostheses fabrication. Modern machines can utilize a broad array of metals, ceramics, and resins. Of most interest in prosthodontics are the highstrength ceramics (alumina and zirconia) that constitute a durable metal-free restoration material and can only be produced by computer-aided manufacturing [3, 18]. Prior to computer-aided manufacturing, metal-free restorations were prone to fracture and primarily reliable for single anterior tooth restorations. High-strength ceramics expand the indications for ceramic restorations to include multiunit prostheses and posterior teeth restorations.

A modified application of digital dentistry is the quantification of the effect of the proposed treatment prior to the active treatment phase. This takes advantage of the software precision in measurements and quantification. On the $3 \mathrm{D}$ models, volumes and distances can be precisely measured
[19], and in the dental practice, analysis of tooth preparation can occur prior to prosthesis fabrication. In some instances, where the tooth preparation is not ideal or restoration thickness is minimal, modifications of the tooth preparation can be recommended to reduce the risk of mechanical failure of the prosthesis. Such feature can be coupled with a digital wax-up to ensure that any tooth preparation will facilitate the planned restoration [20]. Several authors have discussed models analysis and surveying for removable partial denture framework fabrication $[21,22]$. This feature will locate the ideal path of insertion and abutment tooth undercuts and, subsequently, the ideal location of components and prosthesis design will be selected.

In prosthodontics, the early application of computeraided manufacturing was to produce fixed prosthesis luted to teeth $[13,15,23-25]$. Systems have subsequently been developed to fabricate implant components and prostheses $[17,26]$. In prosthodontics today, utilizing computerized technologies to fabricate prostheses is an acceptable treatment modality. Materials such as ceramics, metals (base metal alloys and titanium), resins, and waxes can be processed by the existing systems $[12,23,26]$. In addition, computerized technologies are used to plan and idealize surgical implant treatment [27-29]. Due to the precision that can be achieved with the aid of information from 3D digital radiographs, implant dimensions and placement locations can be determined using planning software without violation of critical anatomical features. Further, the need for bone and/or soft tissue grafting can be established.

A recent application of computer-aided manufacturing is the fabrication of removable prostheses. Removable partial denture metal frameworks can be produced directly from metal $[21,22,30]$ or, alternatively, a resin pattern framework can be formed and then cast using conventional fabrication methods [31, 32]. Different computerized protocols have been proposed for the fabrication of complete denture bases [3337] and are very useful for fabricating facial prosthesis [10], as the morphologies can be easily obtained by mirror image or average face form $[38,39]$ so that a more realistic and natural prosthesis can be manufactured [40]. A map of the surface morphology and colour can be saved virtually which facilitates future prosthesis fabrication. As extraoral scanning is a possibility, the whole experience will also be much more comfortable to the patient $[40,41]$. The automated process will significantly reduce the reliance on technical skill and human variation. With the available systems, facial prosthesis can be produced from resin or wax [40-42]. Subsequently, it is invested and transformed to surgical grade silicone. In addition to prosthesis design, computerized planning also allows surgical idealizing of the defect site prior to prosthetic rehabilitation [10].

\section{Computer-Aided Production Streams}

Once the design of the prosthesis is completed by a computeraided design (CAD) software, the data is transferred to a computer-aided manufacturing (CAM) software that controls the production unit. The aim of computer aidedmanufacturing is to produce an accurate restoration with 
an accurate fit and correct morphology as designed by the CAD software. The following is a detailed discussion about subtractive and additive manufacturing. Special emphasis is placed on the materials effect and accuracy.

\subsection{Subtractive Manufacturing}

3.1.1. Description. Subtractive manufacturing is based on milling the workpiece from a larger blank by a computer numeric controlled (CNC) machine. The CAM software automatically translates the CAD model into tool path for the CNC machine. This involves computation of the commands series that dictate the CNC milling, including sequencing, milling tools, and tool motion direction and magnitude [24]. Due to the unevenness of the features of dental restoration, the milling machines combine burs with different sizes. The accuracy of tool positioning has been reported to be within $10 \mu \mathrm{m}$ [24]. The CAM software also incorporates compensation steps for the cutter tool diameter which ensures that the milling bur reaches the desired surface without sacrificing necessary segment of the workpiece [24, 43].

The dental CNC machines are composed of multiaxis milling devices to facilitate the 3D milling of dental work pieces (Figure 1). The 3-axis milling systems are the most commonly used in dental milling systems. In such systems, the milling burs move in three axes $(x-, y$ - and $z$-axes) according to calculated path values. Therefore, 3 -axis milling has the advantage of having minimal calculation and cumulative milling time [12]. In industry, 3-axis machines cannot produce convergence, divergence, and highly defined features or mill all the surfaces, unless the specimen is manually relocated. For the dental application, $180^{\circ}$ rotation of the blank is incorporated within the machine, allowing $3 \mathrm{D}$ milling of the internal and external surfaces, producing divergence and convergence of the milled surfaces, and establishing greater definition of the surface features $[12,24]$. Further, the speed of milling can be enhanced by incorporating two milling burs simultaneously. As the movement is restricted to the milling tool, large prosthesis cannot be produced by 3 -axis machines.

In addition to the movements of 3 -axis milling machines, the 4-axis machines allow for blank movements in an additional axis. This is a useful feature for milling a large blank and producing long span frameworks. The 5th axis of 5-axis machines is a rotating path of the milling tool or the blank. This facilitates production of very complex geometries and smooth external surfaces. The smooth surface is produced by the tangential movement of the milling bur. In industry, such machines are useful to manufacture very complex parts (e.g., curved holes). In dentistry, 5-axis machines are suitable for producing complex shapes such as acrylic denture bases [34]. For dental applications, the quality of the restoration is independent of the number of axes; instead, it reflects the method of processing the workpieces and CAD path of milling [12].

3.1.2. Material. The materials processed by subtractive milling are metals, ceramics, resins, and waxes. A key advantage of milling is ensuring the durability of the workpiece

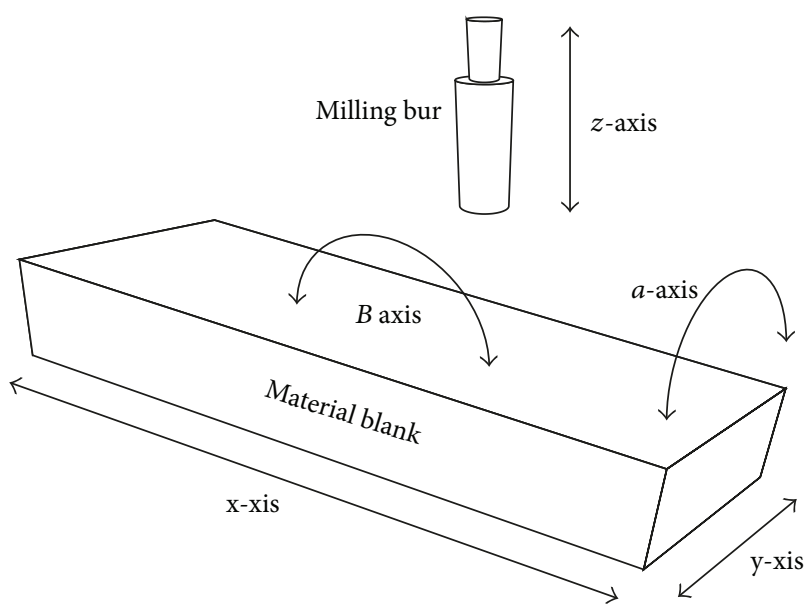

FIGURE 1: Schematic diagram illustrating the different milling axes. $x-, y$-, and $z$-axes are associated with 3 -axis milling system. In addition to $x$-, $y$-, and $z$-axis, 4 -axis milling system has an additional axis ( $a$ - axis). 5-axis milling system involves five axes ( $x_{-}^{-}, y^{-}, z_{-}^{-}, a-$ and $b$-axes).

since it is milled from an industrial grade blank. Milling can reduce fabrication flaws in dental prostheses, by relying more on the tighter quality control processing of the material manufacturer rather than commercial laboratory [44] so that manufacturing deficiencies, such as porosities and inhomogeneous consistency, are reduced $[3,17,18]$.

Before computer-aided manufacturing, the clinical studies reported a reduced longevity of ceramic restorations compared to metal restorations. Initially, only glass ceramics were fabricated using conventional methods. Several studies showed that such materials are acceptable for inlay, onlay, or anterior crowns so long as they were cemented with resin $[45,46]$. However, they exhibit a high failure rate in regions of high load such as posterior teeth [47]. Recently, highly dense ceramics with high flexural strength and fracture toughness were introduced [18]. In comparison to glass ceramics, zirconia can be used to fabricate dental prostheses such as fixed dental prostheses and implant abutments and frameworks where a high occlusal load is expected $[3,26,48]$. To produce the zirconia workpiece, the material should be heat treated to its melting temperature followed by strictly controlled cooling to ensure the zirconia is composed predominantly from the tetragonal phase $[3,49]$. Such a set-up is not available in commercial dental laboratories. Instead, a large blank is industrially produced in a controlled environment and the dental workpieces are subsequently milled to the correct dimensions [18].

Two milling forms are available: hard machining and soft machining. The hard machining is used for metal, densely sintered zirconia, and composite resin while the soft machining is specifically used for presintered zirconia. Hard machining is based on milling the workpiece to its exact dimensions by a robust CNC system. Since it requires milling of blanks with high hardness, the machine has to be very strong to allow for application of heavy cutting forces and cutting power for efficient material removal. Therefore, 
the majority of the cutting power will turn into thermal energy and raise the temperature of the milling tool, which can reduce its life. Further, the surface temperature rise will be accentuated if the milled material is of low thermal conductivity (e.g., titanium and zirconia) [50, 51]. Thus, constant cooling is required to prevent overheating of the milled material [50]. Due to the brittle nature of ceramics, it is very likely that it will be more affected than metal [44]. Subcritical ceramic surface damage could develop in the form of surface microfractures, chipping defects, and altered surface quality $[51,52]$ and could constitute a point for crack propagation within the restoration under occlusal forces [52]. The extent of the damage is dependent on the material of the workpiece [53] and ranges from 15 to $60 \mu \mathrm{m}$ [54-56]. To reduce such complications, milling is better accomplished in two steps: a first rough milling is done at a low feed rate and high cutting force while the final fine milling is performed at a higher feed rate and reduced cutting forces $[18,44]$. The fine milling will reduce the chip thickness and minimise surface roughness [57-59]. In relation to zirconia milling, common disadvantages of hard machining are that it is time consuming and that the zirconia phase transformation to monoclinic phase occurs $[18,44,60]$. Such a phase transformation will exacerbate surface microcracking and low thermal degradation.

Consequently, soft machining or dry processing has been adopted by several manufacturers for the purpose of simplifying the milling and to improve time efficiency. Soft machining is based on the milling of an oversized piece of a presintered zirconia workpiece followed by sintering. The milled zirconia is at the presintered state and the composition differs from the hard machined zirconia to reduce its hardness which enhances the machinability. The sintering procedure will cause about $25-30 \%$ shrinkage of the workpiece [18]. This approach has the advantages of quicker milling, reduce cutting forces, increase the tool life, potentially better surface quality, and no moisture absorption of the zirconia blanks which omits the need for drying the milled zirconia prior to sintering $[3,12,18]$. Further, as the milled presintered zirconia will be sintered, it will have a more consistent tetragonal phase on the surface than hard machined zirconia. The risk with this procedure is the increased dimensional discrepancy in comparison to hard machined zirconia which has been reported in laboratory and clinical studies [61, 62]. Nevertheless, the continuous improvements in soft machining of zirconia reflect a now reliable shrinkage compensation mechanism [63].

Clinically, although there are several advantages of zirconia, it exhibits inherent limitations such as a high incidence of ceramic veneer fracture and material instability $[18,61]$. In order to reduce such complications, different strategies have been proposed. The zirconia should be produced with accurate dimensions so the need for manual adjustment is eliminated. Postsintering adjustment can lead to phase transformation defect introduction to the zirconia and subsequent weakening of the zirconia framework [3, 18, 44, 64]. Several authors have reported increasing the zirconia thickness to enhance its clinical durability [65-68]. This could be easily incorporated with digital production systems. Full customization of the zirconia framework will ensure maximal bulkiness of the material that has been shown to enhance the durability of a zirconia prosthesis $[69,70]$. In addition, it will provide more support to the veneering ceramic or reduce the thickness of the veneering ceramic that reduces the possibility of ceramic chipping $[65,66]$. More recently, monolithic zirconia prostheses have been proposed where the prosthesis is entirely fabricated from zirconia. Such treatment modality appears to be promising for tooth-supported prostheses [71] and implant-supported prostheses [72]. This appears to be coming from a more popular option especially with the increased application of stained or translucent zirconia that overcomes the problem of high value of zirconia $[73,74]$.

In vitro studies have confirmed that zirconia prostheses are not as durable as metal prostheses. This is true for toothsupported prostheses and implant-supported prostheses [75, 76]. However, it has also been confirmed that the durability of zirconia prostheses is within a clinically acceptable range to withstand physiological occlusal forces. This is supported by clinical studies that show that substructures made from zirconia are suitable for copings, fixed dental prostheses, implant abutments, and implant frameworks [77-81].

3.1.3. Accuracy. As stated earlier, milling is anticipated to eliminate waxing, investing, and casting of prostheses which is assumed to improve the overall precision. However, there is a lack of compelling evidence supporting this assumption for tooth-supported restorations [82, 83], because, in terms of fit, there is an overall tendency for the restorations produced by conventional methods to exhibit better fit than milled restorations. This applies to milled metal $[83,84]$ and ceramic restorations [85]. In relation to milled titanium, Tan et al. found that milled titanium crowns exhibited a vertical gap of $79.4 \mu \mathrm{m}$, while cast noble metal crowns had vertical opening of $23.9 \mu \mathrm{m}$ [83]. In a similar study, Han et al. compared the marginal accuracy of milled titanium and cast titanium crowns [84]. There was a tendency for a smaller marginal opening for cast titanium $(52-76 \mu \mathrm{m})$ than CAD/CAM titanium $(60-80 \mu \mathrm{m})$. In relation to lithium disilicate, milled ceramic veneers tended to exhibit horizontal $(231.0 \mu \mathrm{m})$ and vertical $(545.8 \mu \mathrm{m})$ gaps twice those of pressed veneers (horizontal gap $=105.6 \mu \mathrm{m}$ and vertical gap $=242.4 \mu \mathrm{m}$ ) [85]. This difference was significant enough to be associated with more microleakage. A systematic review revealed that more fit discrepancies of zirconia frameworks were associated with soft machining, prosthesis curvature, and span length [82].

However, fit problems might not be purely from milling. Two factors could explain the limited accuracy of the CAD/CAM protocols. The first factor is related to the familiarity and the associated learning curve in relation to restoration fabrication following the CAD/CAM protocols compared with the well-established conventional protocol. The second factor is although multiple steps are omitted, the CAD/CAM protocol introduces additional steps in the fabrication process which may result in the introduction of inaccuracies. Steps such as scanning, locating the margin digitally, software modelling, and milling will inevitably introduce source of inaccuracy $[51,86]$. 


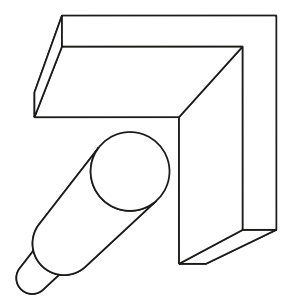

(a)

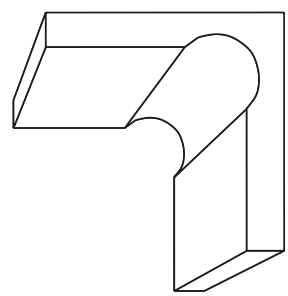

(b)

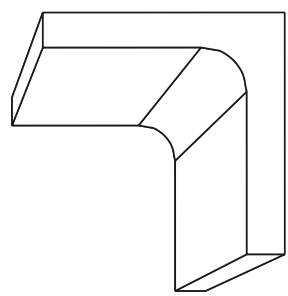

(c)

Figure 2: The effect of bur diameter in internal line angle production. (a) Sharp virtual line angle cannot be produced by rounded bur. Therefore, internal surface inaccuracy will occur on the milled restoration in the form of (b) negative error after overmilling of the sharp corner or (c) positive error after undermilling of the sharp corner.

The production of the fine details by milling is largely dependent on the diameter of the smallest milling bur which is normally about $1 \mathrm{~mm}[12,24,43]$; however, smaller diameter milling burs do not appear to produce fine detail for accuracy $[86,87]$. Örtorp et al. reported that, in order to mill the internal angle with a diameter less than the diameter of the smallest fitting bur, a drill compensation feature has to be incorporated within the software to provide room for the bur movement (Figure 2) [43]. When used, however, this feature was found to produce negative fit errors and dramatically increase the internal space between the restoration and the prepared tooth surface. Excessive cement space has been attributed to a compromise in the mechanical durability of a restoration [88]. Excessive cement space also results in a loose fitting restoration that may affect the accuracy of seating the restoration, resulting in occlusal interferences, horizontal marginal discrepancies, and a loss in retention of the restoration [89]. Further, in cases with limited occlusal space, the final restoration thickness will be reduced, which increases the susceptibility of a mechanical failure. If cement space is not incorporated, however, positive errors will be produced and the restoration will not fit unless manually modified. Problems created by incorrect cement space can be minimised by incorporating rounded line angles on the tooth preparation. Doing so will minimise the impact of the drill compensation as the edge diameter can accommodate the bur diameter [3, 12]. In addition, a smooth and continuous preparation surface with minimal irregularities and welldefined preparation margins will enhance the quality of the milled restoration (Figure 3 ).

Milling accuracy is dictated by materials properties. High material hardness means low machinability and more involved forces [90]. Titanium and densely sintered zirconia are difficult to machine, rendering the bur more susceptible to tool failure and wear [50, 90-92]. Consequently, the internal surface might be under-milled, hindering the fit of the restoration [43]. In addition, the hardness of these materials means that they are more prone to surface chipping and chattering especially under high feed rates, high cutting speed, and deficient cooling $[91,93]$. These cutting conditions also cause excessive vibrations and exert thermal and mechanical stresses on the workpiece, which contributes to dimensional distortions, especially in thin edges [94]. To overcome these limitations, regular maintenance and bur replacement have been advised [43].
A clinically acceptable margin is within $100 \mu \mathrm{m}[95,96]$, and while there is a significant difference reported in the laboratory studies, these may not be of clinical significance. It is worth noting however that an "adaptation step" was included in many of the studies where the investigators manually modified the internal surface of the CAD/CAM framework with a fine grit size diamond bur to eliminate internal premature contacts [62, 97-99]. The rationale behind this manual refinement was to eliminate internal binding surfaces which prevented adequate seating at the crown margin allowing a better marginal fit to be obtained [100]. Although this step clearly enhances the fit of the final restoration, it also indicates a deficiency of the CAD/CAM systems in producing accurately fitting restorations.

On the contrary, implant milled prostheses were consistently better fitting than conventionally fabricated implant prostheses $[101,102]$. This observation was correct for components fabricated from metal and ceramic. The vertical gap for milled titanium and zirconia abutments was reported to be in the range of 2.5-3.2 $\mu \mathrm{m}$ [103]. Further, the rotational movement was reported to be minimal (less than $3^{\circ}$ ) [104]. In relation to implant frameworks, milling consistently provides very accurately fitting frameworks with a vertical fit in the range of 1 to $27 \mu \mathrm{m}$, and the influence of prosthesis span appears to be minimal $[105,106]$, which is opposite to the observation for cast metal frameworks [107]. Milled abutments have also been shown to have minimal roughness with a well-defined geometry edge and a vertical gap of $0.7 \mu \mathrm{m}$. This is superior to abutments produced by selective laser melting (vertical gap $=11.3 \mu \mathrm{m})$ or casting (vertical gap $=$ $9.1 \mu \mathrm{m})[108]$.

The superior accuracy of milled implant components compared to tooth-supported restorations could be due to the simple and accurate numerical representation of the geometry of the implant components. This reduces the reliance on the scanning function to register the location and orientation of the implants, and no milling compensation feature is required for the implant framework or abutment [17].

\subsection{Additive Manufacturing}

3.2.1. Description. Additive manufacturing systems have recently been introduced as a method to construct dental 


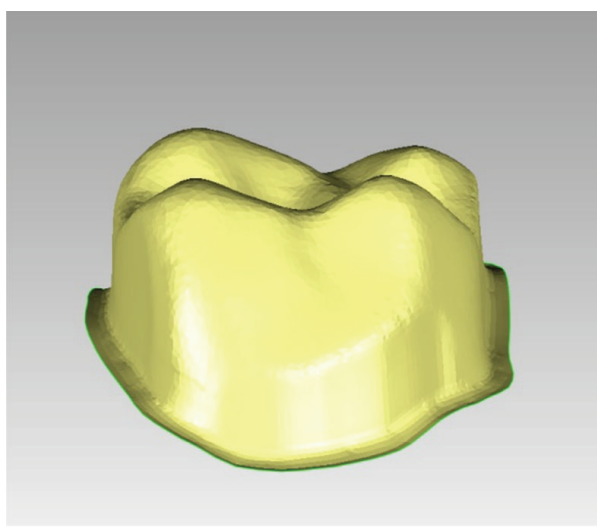

(a)

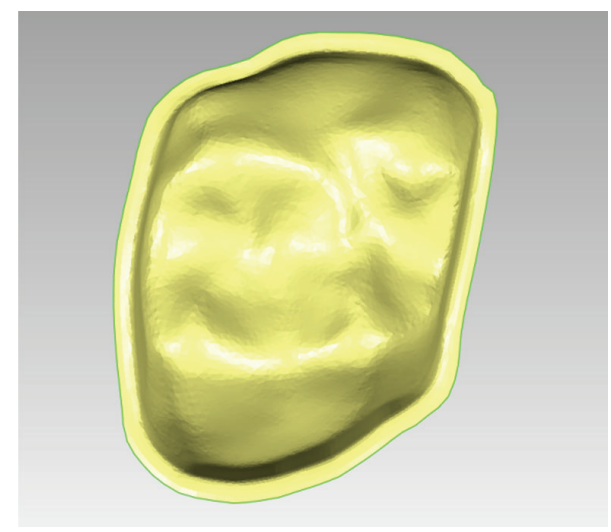

(b)

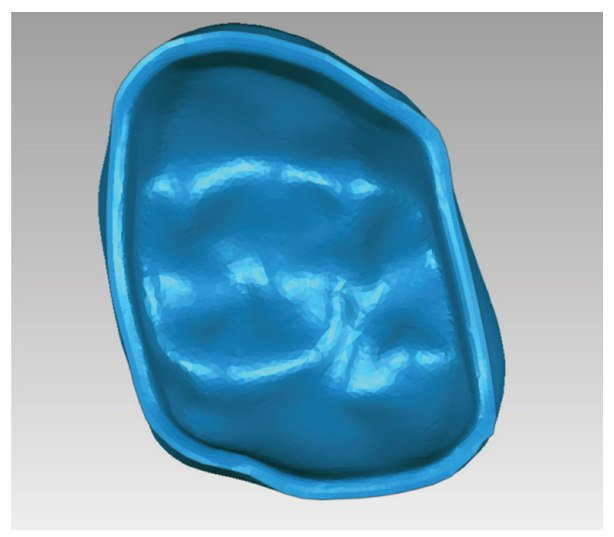

(c)

FIGURE 3: (a) Side and (b) occlusal image of prepared tooth illustrating smooth and continuous surfaces and well-defined preparation margin. Such preparation features will enhance the accurate milling of the final restoration. (c) The rounded features of the virtual restoration fitting surface can easily accommodate the milling burs.

restorations and medical devices. Additive manufacturing is defined as the process of joining materials to make objects from 3D model data, usually layer upon layer [10, 16, 109]. Once the CAD design is finalized, it is segmented into multislice images. For each millimetre of material, there are 5-20 layers, which the machine lays down as successive layers of liquid or powder material that are fused to create the final shape. This is followed by workpiece refinement to remove the excess materials and supporting arms. Similar to the subtractive systems, a form of CNC machine is used with a processing head that moves in two axes ( $x$ - and $z$-axes) and the specimen platform or the processing head moves in the vertical axis ( $y$-axis) [110,111].

Originally, the additive manufacturing methods were implemented to fabricate prototype models and patterns with reliable accuracy and repeatability that could be produced in a short time. In prosthodontics, additive manufacturing can fabricate a preproduction pattern (wax or plastic) that can be transformed to a definitive prosthesis, and it can directly produce definitive workpieces in metals, resins, or ceramics $[10,16,109]$. The application of additive manufacturing in dentistry is due to its ability to produce a variety of shapes that conform to any biological site. The additive systems used in dentistry are stereolithography, selective laser sintering or melting, and 3D printing. Regardless of the method, all share the following features that distinguish them from subtractive manufacturing:

(i) incremental vertical object build-up

(ii) no material wastage

(iii) large objects produced

(iv) passive production (i.e., no force application)

(v) fine details production.

Selective laser sintering or selective laser melting produces a 3D model by laser sintering or melting a powder, layer by layer using a laser beam (Figure 4(a)). The laser beam locally raises the temperature close to the melting point of the metal particle, to avoid complete melting [112, 113]. The platform is slightly immersed in the powder, and powder thickness is controlled by a cylinder rolling on the powder pool. After each new powder layer application, the laser melting process is repeated until the $3 \mathrm{D}$ object is completed. Oxidation of the metal can be controlled by confining the melting to a sealed gas chamber. The term selective laser sintering is used to describe the fabrication of a pattern from ceramics or polymers while selective laser melting describes 


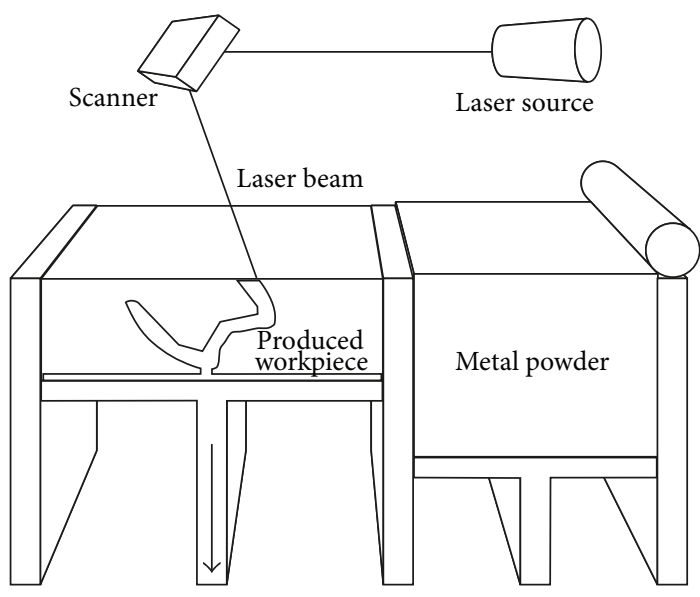

(a)

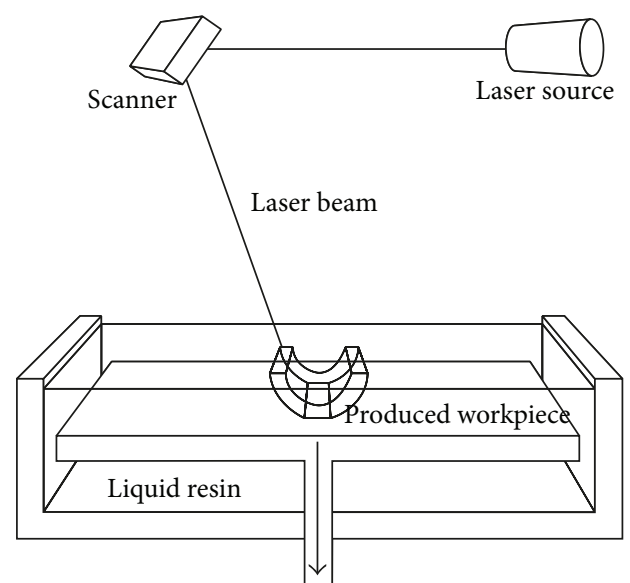

(b)

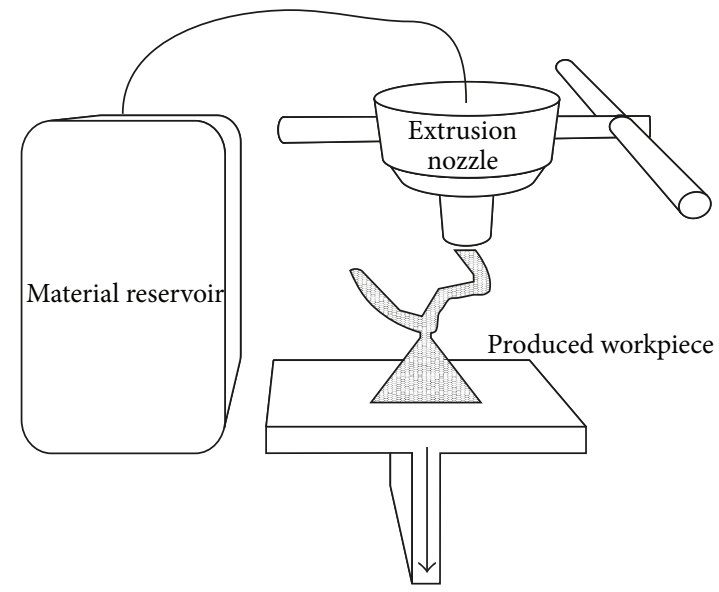

(c)

FIGURE 4: Schematic diagrams of the different additive manufacturing apparatus. (a) Selective laser melting. (b) Stereolithography. (c) 3D printing. The arrows indicate the direction of platform movement.

pattern fabrication from metal [16]. Selective laser melting is the only additive method that is available to produce metal workpieces such as crowns, fixed dental prostheses, or removable partial denture frameworks. Further, this technique can produce customized implants for maxillofacial applications or joint replacement.

Stereolithography produces the solid layers using a concentrated ultraviolet light beam that moves on a curable liquid polymer pool (Figure 4(b)). As the first layer is polymerized, a platform is lowered a few microns and the next layer is cured. This process is repeated until the whole solid object is completed. The object is then rinsed with a solvent and placed in an ultraviolet oven to thoroughly cure the resin. In dentistry, stereolithography is routinely used to produce resin objects such as surgical templates for oral and extraoral implant placement and preprosthetic surgery. Additional applications of stereolithography are the fabrication of facial prosthesis patterns, occlusal splints [114], burnout resin patterns [115], and investing flasks [116]. With the aid of multislice CT data, real size anatomical models of a patient can also be replicated to facilitate visualization of bone anatomy [117]. Further, these anatomical models can be used to assist with the fabrication of customized implants for hard tissue reconstruction.

3D printing extrudes material from a nozzle that solidifies as soon as it is deposited on the manufacturing platform (Figure 4(c)). The layer pattern is achieved through horizontal nozzle movement and interrupted material flow. This is followed by vertical movement for the sequential layer deposition. There are a range of materials that can be used for 3D printing. This includes thermoplastic materials, such as waxes, resins, or fused filament, which pass through a heated nozzle and solidifies immediately after extrusion. Alternatively, liquid ceramic or resin materials with a binder can be printed [35, 118], which, following deposition, solidifies immediately $[119,120]$. Some systems also allow for multicolour production [118]. This approach is used in dentistry to fabricate dental models, facial prosthesis patterns, acrylic prostheses, investing flasks, and castable or ceramic frameworks $[35,118]$. 3D printing is distinguished from other fabrication methods in the ability to print multiple materials at one time [119]. 


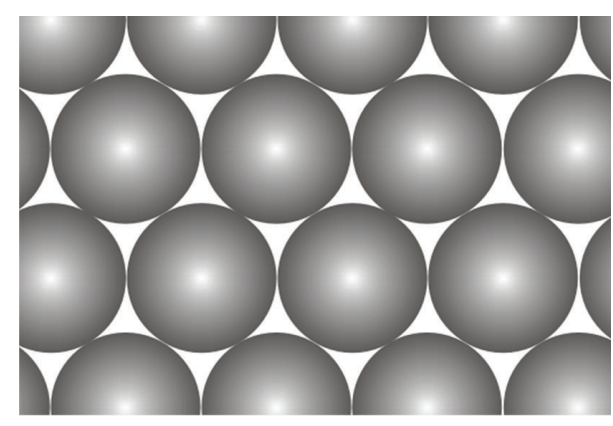

(a)

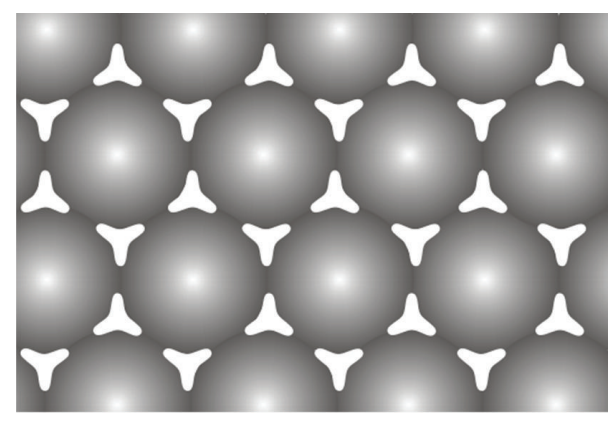

(b)

Figure 5: The effect of selective laser melting of metal powder. (a) Premelted metal particles. (b) Postmelting figure illustrates the necks formation between the particles.

3.2.2. Material. Material selection depends on the purpose of the prosthesis and the manufacturing procedure. In comparison to subtractive processing, this method is more economical since it does not result in any material wastage, and any unused material is completely reusable for future processing $[10,109]$. In addition, there is minimal restriction on the ability to fabricate large workpieces (e.g., facial prosthesis and skeleton models), which is not the case with subtractive methods that are more suitable for smaller workpieces [40-42]. Additive manufacturing also allows the fabrication of workpieces with different consistencies and material properties [121].

Some prostheses serve for aesthetic purposes, such as facial prostheses, and significant durability is not a requirement. Instead, rapid manufacturing is beneficial as it allows the production of several prosthesis duplicates. In comparison, for an intraoral prosthesis to be functional, it should be durable enough to withstand occlusal loads. It is well reported that the metal pattern produced by selective laser melting exhibits microporosities, in the range of 30$45 \%[113,121]$. Porosity was also observed in the dental frameworks produced by selective laser melting [22] and has been attributed to the selective melting process [113, 122]. As laser melting takes place, the external surface of the metal transforms to a liquid phase. The liquidised surface flows and fills the pores between the metal particles and solidifies to form a continuous solid phase. Greater liquid flow between the metal particles and lower initial porosity results in the production of a low porosity microstructure. The selective melting process should not, however, completely melt the metal particles; otherwise, the melted particles will aggregate and form larger spheres [112, 113, 122], resulting in major dimensional discrepancies in the final workpiece $[112,113]$. To avoid this, the metal particles should be heated to just below the melting temperature to ensure melting is confined to the external surface of the particles and fusion contact forms necks between the adjacent powder particles (Figure 5).

Reducing the porosity is desirable as it will increase the tensile strength of the framework $[112,113]$. Certain parameters can be modified by the manufacturer. For example, smaller particle sizes, greater loose powder density, higher laser intensity, reduced scan speed, and smaller layer thicknesses will contribute to increased product density. However, this should be weighed against the potential risk for increased dimensional error, as greater laser power and a lower scan speed can result in greater distortion [112]. Continuous improvements appear to be promising and high metal density is achievable with ideal manufacturing parameters [123].

Porosity was reported to be advantageous for implant fabrication as it produces implants with similar elasticity to bone [124]. Further, the porous structure facilitates ingrowth of bone that can promote osseointegration $[125,126]$. However, such advantages should be accepted with caution as the mechanical durability could be reduced considerably [121]. This is especially critical for intraoral prostheses where mechanical durability is necessary for the prosthesis to withstand occlusal loads. Nevertheless, a recent short-term clinical study reported promising outcomes for posterior crowns [127]. Multiunit prostheses are subjected to considerably greater tensile forces and clinical studies are required to support the clinical validity of this manufacturing technique. To overcome problems of the porosity, $\mathrm{Wu}$ et al. utilized additive manufacturing to produce a wax pattern that was eventually cast using the conventional technique [128].

Recently, high-strength zirconia frameworks have been produced by $3 \mathrm{D}$ printing $[119,120,129,130]$. This novel fabrication method is thought to overcome the problems created by milling, such as surface cracking, shrinkage, and material wastage. The zirconia framework is printed from a suspension of nanoscale zirconia particles with an inkjet printer $[119,120]$. Initially, the printed shape is maintained by drying, but the final strength is reached by sintering $[119,120]$.

The reported strength was of the zirconia prosthesis was $764 \mathrm{MPa}$ and the fracture toughness was 6.7 $\mathrm{MPam}^{0.5}$ [120]. SEM imaging of the printed and sintered zirconia revealed a homogeneous microstructure; however, submicron-sized pores were also detected and attributed to the clogging of nozzles during the injection of zirconia paste. These defects were found to reduce the strength of zirconia frameworks. It is thought that this problem could be overcome with advances in printing hardware [120]. 


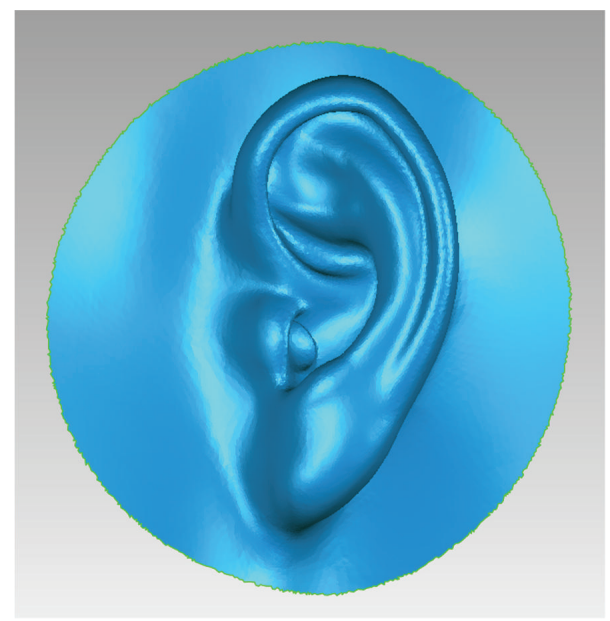

Figure 6: Complex facial features such as corrugation, corners, or tubes can be easily produced by additive manufacturing.

3.2.3. Accuracy. Among the advantages of additive manufacturing is the ability to produce customized workpieces that fit patient hard and/or soft tissues [10, 109]. The workpieces can include detailed morphology, sharp corners, undercuts, or voids. Such features may be desirable for facial prostheses (Figure 6). Because no drilling tool is involved, no compensation feature is required as is necessary for the subtractive manufacturing. Further, the whole production process is passive and involves no force application. However, due to the production procedure, which involves sequential layering, the external surface tends to have stepped and coarse morphology representing each fabrication layer along the construction direction [110]. Such stepping adversely affects the surface texture and the overall dimensional accuracy of the workpiece [110], which could be a problem clinically if the prosthesis is not polished or veneered [22, 31] (Figure 7). The vertical walls were minimally affected by stepping while the corrugated or sloping surfaces are more prominently influenced [123]. Therefore, concerns have also been raised regarding the accuracy of the occlusal surface of prostheses produced using this technique [119]. The accuracy of additive technique is dependent on layer thickness and the width of curing beam. The thinner the layers and the narrower the curing beam, the more accurate the final product; however, increasing the number of layers and reducing the diameter of the beam will exponentially increase the fabrication time $[110,112,113]$.

In the dental literature, there are a limited number of studies that have evaluated the accuracy of prostheses fabricated by additive manufacturing. In relation to selective laser melting, the dimensional accuracy of metal workpieces has been reported to be in the range of $3-82 \mu \mathrm{m}$, which is clinically suitable for intraoral prosthesis [113, 123, 131]. Accuracy can be adjusted by controlling particle diameter $(30 \mu \mathrm{m})$ and layer thickness $(50-200 \mu \mathrm{m}$ each) $[113,122]$. The smaller the dimensions, the greater the accuracy and the density of the final product. Increasing laser intensity and melting time is desirable to increase the density of the workpiece, but this should be weighed against the increase in dimension error that can occur as a result [112]. Although the distortion of each layer is minimal, the accumulated error for all the layers can cause a measurable error [132]. The manufacturer should therefore control the processing parameters, to ensure ideal parameters for a given application [113].

In dentistry, the accuracy of selective laser melting production has been evaluated primarily by assessing the fit of the dental prosthesis. Quante et al. found that the marginal fit of crown copings produced by selective laser melting of noble metal alloy and base metal was in the range of 67 to $99 \mu \mathrm{m}$ which is within the acceptable clinical range [133]. In the same study, the copings of the two alloys were minimally affected by ceramic veneer application. This suggests that alloy selection has minimal influence on the accuracy of selective laser melting. Ucar et al. found that the fit of lasermelted base metal alloy copings is comparable to the fit of cast base metal alloy copings [134], and Örtorp et al. showed that selective laser melting produced fixed dental prosthesis frameworks with almost half the fit discrepancies $(84 \mu \mathrm{m})$ of those produced by milling $(166 \mu \mathrm{m})$ [43]. The latter study also observed a uniform internal fitting surface when compared to milled frameworks that was attributed to the absence of a compensation mechanism in the production process. This outcome was confirmed by Castillo-Oyague et al. who found that copings produced by selective laser melting exhibited half the vertical gap $(25 \mu \mathrm{m})$ of cast copings [135]. The overall dimensional accuracy of selective laser melting has been attributed to the lack of force application and vibration of the machine during production of the workpiece. This feature is of significant importance as it allows the production of delicate and thin structures without causing deformation or recoil of the components. For example, removable partial denture framework components can only be produced by selective laser melting $[22,136]$. Williams et al. also reported that the fit of removable partial denture frameworks produced using the additive manufacturing procedure is comparable to frameworks produced using conventional methods [22].

Although the fit of tooth-supported frameworks produced by selective laser melting may be better than those produced by milling [43], similar findings have not been observed for implant components. Implant abutments produced by selective laser melting have been shown to exhibit greater surface roughness and microgaps compared to machined or cast abutments [108]. Further, the geometry of abutments produced by selective laser melting was blurred in comparison with the sharply defined connection of the milled components. Although the inaccuracies generated by selective laser melting (11 $\mu \mathrm{m}$ vertical gap) still reside within the clinical acceptability range, it reflects system limitations where future improvements are very desirable.

For stereolithography, the range of each layer thickness is $50-150 \mu \mathrm{m}$ [137]. In dentistry, this technique is primarily used to produce surgical implant guides. The accuracy of intraoral implant placement positions has been evaluated to provide an indication of the benefit of surgical implant guides produced by stereolithography and has been found 


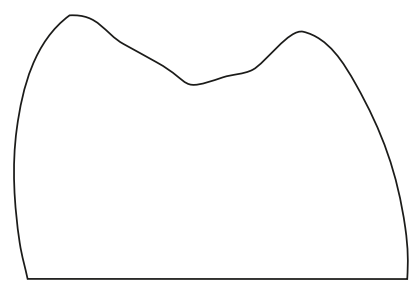

(a)

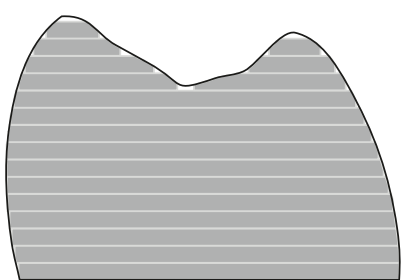

(b)

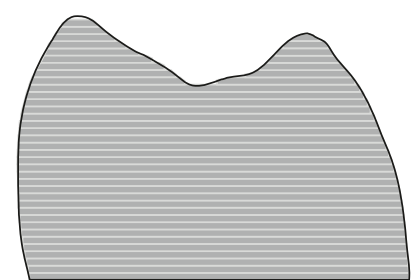

(c)

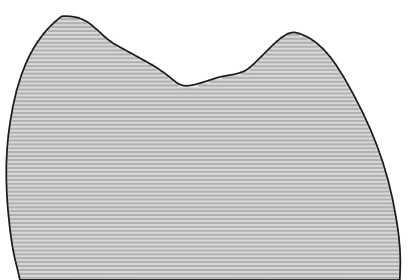

(d)

FIgURE 7: The effect of layered production on the surface accuracy. (a) Smooth surface is ideal for dental restorations. (b) Thick layers will increase the prominence of surface stepping. (c) and (d) As the layers thickness is reduced, the surface accuracy will increase. The corrugated surface (occlusal surface) is more affected by the steps than the vertical surfaces.

to be in the range of $0.4-2.0 \mathrm{~mm}$, and angulations are in the range of $2-5^{\circ}[27,29,138]$. Similarly, extraoral implant placement accuracy was $1.5 \mathrm{~mm}$ [139]. Farley reported that some stereolithography templates required intraoral relining to improve the fit on the adjacent teeth [28]; however, this discrepancy could not be related to manufacturing process. Instead, clinical variability such as soft tissue fit and compressibility and implant insertion in less dense bone may be the main source of the discrepancies [27, 139]. Distortions will also occur in the construction of 3D images from multislice radiographs. Despite this, the discrepancies observed endorse the clinical recommendation that these techniques do not eliminate the importance of surgeon experience, awareness of critical anatomical features, and the maintenance of a safe zone of $2 \mathrm{~mm}$ from critical features such as adjacent teeth when planning implant placement [29]. Overall, the accuracy of the surgical guides could be improved by fabricating them to fit the alveolar bone instead of soft tissue and by the use of fixation screws [27, 29]. Nevertheless, a split mouth clinical study revealed that the stereolithography guides allowed for implant placement closer to the planned position than conventionally fabricated guides [28].

In general, stereolithography provides good overall contour of facial prosthesis, with several authors reporting well-fitting facial prostheses fabricated by stereolithography [41]. The range of accuracy of the facial prosthesis pattern fabricated by this method resides in the range of $0.1-0.4 \mathrm{~mm}$ $[7,140]$.

Salmi et al. reported the dimensional accuracy of occlusal splits fabricated by stereolithography to be $0.3 \mathrm{~mm}$ [114]; however, true quantification of fit was not conducted. Overall, the margins were less than ideal which could be due to the stepping surface feature $[40,42]$. Some authors have suggested wax relining prior to investing the pattern to compensate for these inaccuracies [40]; however. with regular advances in development of the software and hardware, it is very likely that this problem is of minimal impact.

There is very limited data on the accuracy of $3 \mathrm{D}$ printing for dental applications. Ebert et al. reported that this method allows the fabrication of very accurate ceramic workpieces [120], and the production of sections of $100 \mu \mathrm{m}$ is feasible. Silva et al. reported that the tolerance of the fabricated workpiece is less than $25 \mu \mathrm{m}$, which is very acceptable for intraoral application [119]. In comparison, an evaluation of the dimensional errors of printed dentures found a mean deviation of $5 \mu \mathrm{m}$, but dimensional distortions of up to several $100 \mu \mathrm{m}$ were detected [118]. As the 3D printing of dental prosthesis is still in its infancy, it is very likely that significant quality improvement will occur in the future making this technology very competitive with the existing fabrication methods [119].

\section{Conclusions}

Computer-aided manufacturing continues to undergo significant and regular improvements so that it is very likely that, in the near future, wide acceptance of its use in dentistry will occur. Currently, subtractive milling is the most widely implemented computer-aided manufacturing protocol in dentistry and it has been shown to be a suitable method for fabricating intraoral prostheses. Additive manufacturing is currently an exponentially growing fabrication method and will most likely be used more frequently in dentistry in the future as its accuracy and range of applications develop. In terms of material processing, both techniques introduce material defects. The subtractive methods, however, currently produce more homogenous objects making this method more suitable for the production of intraoral prosthesis that can withstand higher occlusal loads. Additive methods have the advantage of producing large objects, with surface irregularities, undercuts, voids, and hollow morphology that makes them suitable for manufacturing facial prostheses and metal removable partial denture frameworks. Computeraided manufacturing procedures will indisputably change many aspects of dentistry in the future, particularly in relation to treatment simplicity and production time. It is therefore critical for clinicians and technicians to be familiar with the advantages and disadvantages of computer-aided manufacturing as these procedures continue to develop and become an integrated part of dentistry.

\section{Conflict of Interests}

The authors declare that there is no conflict of interests regarding the publication of this paper.

\section{References}

[1] "The glossary of prosthodontic terms," The Journal of Prosthetic Dentistry, vol. 94, no. 1, pp. 10-92, 2005. 
[2] J. C. Wataha and R. L. Messer, "Casting alloys," Dental Clinics of North America, vol. 48, no. 2, pp. 499-512, 2004.

[3] A. Sadan, M. B. Blatz, and B. Lang, "Clinical considerations for densely sintered alumina and zirconia restorations-part 1," International Journal of Periodontics and Restorative Dentistry, vol. 25, no. 3, pp. 213-219, 2005.

[4] L. Fine, "Color and its application in maxillofacial prosthetics," The Journal of Prosthetic Dentistry, vol. 39, no. 2, pp. 188-192, 1978.

[5] L. Fine, J. E. Robinson, G. W. Barnhart, and L. Karl, "New method for coloring facial prostheses," The Journal of Prosthetic Dentistry, vol. 39, no. 6, pp. 643-649, 1978.

[6] J. J. Gary and C. T. Smith, "Pigments and their application in maxillofacial elastomers: a literature review," The Journal of Prosthetic Dentistry, vol. 80, no. 2, pp. 204-208, 1998.

[7] L. M. Sykes, A. M. Parrott, C. P. Owen, and D. R. Snaddon, "Applications of rapid prototyping technology in maxillofacial prosthetics," International Journal of Prosthodontics, vol. 17, no. 4, pp. 454-459, 2004.

[8] D. M. dos Santos, M. C. Goiato, M. A. Sinhoreti et al., "Influence of natural weathering on colour stability of materials used for facial prosthesis," Journal of Medical Engineering \& Technology, vol. 36, no. 5, pp. 267-270, 2012.

[9] J. F. Lontz, "State-of-the-art materials used for maxillofacial prosthetic reconstruction," Dental Clinics of North America, vol. 34, no. 2, pp. 307-325, 1990.

[10] B. K. Davis, "The role of technology in facial prosthetics," Current Opinion in Otolaryngology and Head and Neck Surgery, vol. 18, no. 4, pp. 332-340, 2010.

[11] T. Miyazaki and Y. Hotta, "CAD/CAM systems available for the fabrication of crown and bridge restorations," Australian Dental Journal, vol. 56, no. 1, pp. 97-106, 2011.

[12] F. Beuer, J. Schweiger, and D. Edelhoff, "Digital dentistry: an overview of recent developments for CAD/CAM generated restorations," British Dental Journal, vol. 204, no. 9, pp. 505-511, 2008.

[13] F. Duret and J. D. Preston, "CAD/CAM imaging in dentistry," Current Opinion in Dentistry, vol. 1, no. 2, pp. 150-154, 1991.

[14] W. H. Mörmann, M. Brandestini, F. Lutz, and F. Barbakow, "Chairside computer-aided direct ceramic inlays," Quintessence International, vol. 20, no. 5, pp. 329-339, 1989.

[15] M. Andersson, L. Carlsson, M. Persson, and B. Bergman, "Accuracy of machine milling and spark erosion with a CAD/CAM system," The Journal of Prosthetic Dentistry, vol. 76, no. 2, pp. 187-193, 1996.

[16] R. van Noort, "The future of dental devices is digital," Dental Materials, vol. 28, no. 1, pp. 3-12, 2012.

[17] J. Abduo and K. Lyons, "Rationale for the use of CAD/CAM technology in implant prosthodontics," International Journal of Dentistry, vol. 2013, Article ID 768121, 8 pages, 2013.

[18] I. Denry and J. R. Kelly, "State of the art of zirconia for dental applications," Dental Materials, vol. 24, no. 3, pp. 299-307, 2008.

[19] G. R. Davis, R. A. Tayeb, K. G. Seymour, and G. P. Cherukara, "Quantification of residual dentine thickness following crown preparation," Journal of Dentistry, vol. 40, no. 7, pp. 571-576, 2012.

[20] J. Abduo, "Virtual prosthodontic planning for oral rehabilitation: a pilot study," in Proceedings of the Workshop on New Trends of Computational Intellegence in Health Applications, pp. 34-42, Sydney, Australia, 2012.
[21] J. Han, Y. Wang, and P. Lü, "A preliminary report of designing removable partial denture frameworks using a specifically developed software package," The International Journal of Prosthodontics, vol. 23, no. 4, pp. 370-375, 2010.

[22] R. J. Williams, R. Bibb, D. Eggbeer, and J. Collis, "Use of CAD/CAM technology to fabricate a removable partial denture framework," The Journal of Prosthetic Dentistry, vol. 96, no. 2, pp. 96-99, 2006.

[23] T. Miyazaki, Y. Hotta, J. Kunii, S. Kuriyama, and Y. Tamaki, "A review of dental CAD/CAM: current status and future perspectives from 20 years of experience," Dental Materials Journal, vol. 28, no. 1, pp. 44-56, 2009.

[24] E. D. Rekow, A. G. Erdman, D. R. Riley, and B. Klamecki, "CAD/CAM for dental restorations-some of the curious challenges," IEEE Transactions on Biomedical Engineering, vol. 38, no. 4, pp. 314-318, 1991.

[25] M. Andersson, M. E. Razzoog, A. Odén, E. A. Hegenbarth, and B. R. Lang, "Procera: a new way to achieve an all-ceramic crown," Quintessence International, vol. 29, no. 5, pp. 285-296, 1998.

[26] A. Kollar, S. Huber, E. Mericske, and R. Mericske-Stern, "Zirconia for teeth and implants: a case series," International Journal of Periodontics and Restorative Dentistry, vol. 28, no. 5, pp. 479487, 2008.

[27] M. Cassetta, L. V. Stefanelli, M. Giansanti, and S. Calasso, "Accuracy of implant placement with a stereolithographic surgical template," The International Journal of Oral \& Maxillofacial Implants, vol. 27, no. 3, pp. 655-663, 2012.

[28] N. E. Farley, K. Kennedy, E. A. McGlumphy, and N. L. Clelland, "Split-mouth comparison of the accuracy of computergenerated and conventional surgical guides," The International Journal of Oral \& Maxillofacial Implants, vol. 28, no. 2, pp. 563$572,2013$.

[29] D. M. Vieira, B. S. Sotto-Maior, C. A. Barros et al., "Clinical accuracy of flapless computer-guided surgery for implant placement in edentulous arches," The International Journal of Oral \& Maxillofacial Implants, vol. 28, no. 5, pp. 1347-1351, 2013.

[30] D. Eggbeer, R. Bibb, and R. Williams, “The computer-aided design and rapid prototyping fabrication of removable partial denture frameworks," Proceedings of the Institution of Mechanical Engineers H: Journal of Engineering in Medicine, vol. 219, no. 3, pp. 195-202, 2005.

[31] R. J. Williams, R. Bibb, and T. Rafik, "A technique for fabricating patterns for removable partial denture frameworks using digitized casts and electronic surveying," The Journal of Prosthetic Dentistry, vol. 91, no. 1, pp. 85-88, 2004.

[32] F. Wu, X. Wang X, and Zhoa, "A study on the fabrication method of removable partial denture framework by computer-aided design and rapid prototyping," Rapid Prototyping Journal, vol. 18, no. 4, pp. 318-323, 2012.

[33] Y. Maeda, M. Minoura, S. Tsutsumi, M. Okada, and T. Nokubi, "A CAD/CAM system for removable denture-part I: fabrication of complete dentures," The International Journal of Prosthodontics, vol. 7, no. 1, pp. 17-21, 1994.

[34] M. Kanazawa, M. Inokoshi, S. Minakuchi, and N. Ohbayashi, "Trial of a CAD/CAM system for fabricating complete dentures," Dental Materials Journal, vol. 30, no. 1, pp. 93-96, 2011.

[35] Y. Sun, P. Lü, and Y. Wang, "Study on CAD\&RP for removable complete denture," Computer Methods and Programs in Biomedicine, vol. 93, no. 3, pp. 266-272, 2009.

[36] M. T. Kattadiyil, C. J. Goodacre, and N. Z. Baba, "CAD/CAM complete dentures: a review of two commercial fabrication 
systems," Journal of the California Dental Association, vol. 41, no. 6, pp. 407-416, 2013.

[37] C. J. Goodacre, A. Garbacea, W. P. Naylor, T. Daher, C. B. Marchack, and J. Lowry, "CAD/CAM fabricated complete dentures: concepts and clinical methods of obtaining required morphological data," The Journal of Prosthetic Dentistry, vol. 107, no. 1, pp. 34-46, 2012.

[38] Z. H. Feng, Y. Dong, S. Z. Bai et al., "Virtual transplantation in designing a facial prosthesis for extensive maxillofacial defects that cross the facial midline using computer-assisted technology," The International Journal of Prosthodontics, vol. 23, no. 6, pp. 513-520, 2010.

[39] L. Ciocca and R. Scotti, "CAD-CAM generated ear cast by means of a laser scanner and rapid prototyping machine," The Journal of Prosthetic Dentistry, vol. 92, no. 6, pp. 591-595, 2004.

[40] Z. Feng, Y. Dong, Y. Zhao et al., "Computer-assisted technique for the design and manufacture of realistic facial prostheses," British Journal of Oral and Maxillofacial Surgery, vol. 48, no. 2, pp. 105-109, 2010.

[41] C. Runte, D. Dirksen, H. Deleré et al., “Optical data acquisition for computer-assisted design of facial prostheses," International Journal of Prosthodontics, vol. 15, no. 2, pp. 129-132, 2002.

[42] L.-H. Chen, S. Tsutsumi, and T. Lizuka, "A CAD/CAM technique for fabricating facial prostheses: a preliminary report," International Journal of Prosthodontics, vol. 10, no. 5, pp. 467477, 1997.

[43] A. Örtorp, D. Jönsson, A. Mouhsen, and P. Vult von Steyern, "The fit of cobalt-chromium three-unit fixed dental prostheses fabricated with four different techniques: a comparative in vitro study," Dental Materials, vol. 27, no. 4, pp. 356-363, 2011.

[44] D. Rekow and V. P. Thompson, "Near-surface damage-a persistent problem in crowns obtained by computer-aided design and manufacturing," Proceedings of the Institution of Mechanical Engineers H: Journal of Engineering in Medicine, vol. 219, no. 4, pp. 233-243, 2005.

[45] K. A. Malament and S. S. Socransky, "Survival of dicor glassceramic dental restorations over 14 years-part I. Survival of dicor complete coverage restorations and effect of internal surface acid etching, tooth position, gender, and age," The Journal of Prosthetic Dentistry, vol. 81, no. 1, pp. 23-32, 1999.

[46] M. Fradeani and M. Redemagni, "An 11-year clinical evaluation of leucite-reinforced glass-ceramic crowns: a retrospective study," Quintessence International, vol. 33, no. 7, pp. 503-510, 2002.

[47] B. Taskonak, J. J. Mecholsky Jr., and K. J. Anusavice, "Fracture surface analysis of clinically failed fixed partial dentures," Journal of Dental Research, vol. 85, no. 3, pp. 277-281, 2006.

[48] J. Tinschert, G. Natt, W. Mautsch, M. Augthun, and H. Spiekermann, "Fracture resistance of lithium disilicate-, alumina-, and zirconia-vased three-unit fixed partial dentures: a laboratory study," International Journal of Prosthodontics, vol. 14, no. 3, pp. 231-238, 2001.

[49] J. R. Kelly and I. Denry, "Stabilized zirconia as a structural ceramic: an overview," Dental Materials, vol. 24, no. 3, pp. 289298, 2008.

[50] M. Kikuchi, "The use of cutting temperature to evaluate the machinability of titanium alloys," Acta Biomaterialia, vol. 5, no. 2, pp. 770-775, 2009.

[51] E. D. Rekow, N. R. F. A. Silva, P. G. Coelho, Y. Zhang, P. Guess, and V. P. Thompson, "Performance of dental ceramics: challenges for improvements," Journal of Dental Research, vol. 90, no. 8, pp. 937-952, 2011.
[52] J. Sindel, A. Petschelt, F. Grellner, C. Dierken, and P. Greil, "Evaluation of subsurface damage in CAD/CAM machined dental ceramics," Journal of Materials Science: Materials in Medicine, vol. 9, no. 5, pp. 291-295, 1998.

[53] C. N. Xu, M. Akiyama, K. Nonaka, and T. Watanabe, "Electrical power generation characteristics of PZT piezoelectric ceramics," IEEE Transactions on Ultrasonics, Ferroelectrics, and Frequency Control, vol. 45, no. 4, pp. 1065-1070, 1998.

[54] J. W. Kim, N. S. Covel, P. C. Guess, E. D. Rekow, and Y. Zhang, "Concerns of hydrothermal degradation in CAD/CAM Zirconia," Journal of Dental Research, vol. 89, no. 1, pp. 91-95, 2010.

[55] R. G. Luthardt, M. S. Holzhüter, H. Rudolph, V. Herold, and M. H. Walter, "CAD/CAM-machining effects on Y-TZP zirconia," Dental Materials, vol. 20, no. 7, pp. 655-662, 2004.

[56] J. Sindel, R. Frankenberger, N. Krämer, and A. Petschelt, "Crack formation of all-ceramic crowns dependent on different core build-up and luting materials," Journal of Dentistry, vol. 27, no. 3, pp. 175-181, 1999.

[57] X. Dong, L. Yin, S. Jahanmir, L. K. Ives, and E. D. Rekow, "Abrasive machining of glass-ceramics with a dental handpiece," Machining Science and Technology, vol. 4, no. 2, pp. 209-233, 2000.

[58] L. Yin, S. Jahanmir, and L. K. Ives, "Abrasive machining of porcelain and zirconia with a dental handpiece," Wear, vol. 255, no. 7-12, pp. 975-989, 2003.

[59] L. Yin, L. K. Ives, S. Jahanmir, E. D. Rekow, and E. Romberg, "Abrasive machining of glass-infiltrated alumina with diamond burs," Machining Science and Technology, vol. 5, no. 1, pp. 43-61, 2001.

[60] H. Wang, M. N. Aboushelib, and A. J. Feilzer, "Strength influencing variables on CAD/CAM zirconia frameworks," Dental Materials, vol. 24, no. 5, pp. 633-638, 2008.

[61] I. Sailer, A. Fehér, F. Filser, L. J. Gauckler, H. Lüthy, and C. H. F. Hämmerle, "Five-year clinical results of zirconia frameworks for posterior fixed partial dentures," International Journal of Prosthodontics, vol. 20, no. 4, pp. 383-388, 2007.

[62] P. Kohorst, H. Brinkmann, J. Li, L. Borchers, and M. Stiesch, "Marginal accuracy of four-unit zirconia fixed dental prostheses fabricated using different computer-aided design/computeraided manufacturing systems," European Journal of Oral Sciences, vol. 117, no. 3, pp. 319-325, 2009.

[63] W. Att, F. Komine, T. Gerds, and J. R. Strub, "Marginal adaptation of three different zirconium dioxide three-unit fixed dental prostheses," The Journal of Prosthetic Dentistry, vol. 101, no. 4, pp. 239-247, 2009.

[64] R. J. Kohal, M. Wolkewitz, and C. Mueller, "Alumina-reinforced zirconia implants: survival rate and fracture strength in a masticatory simulation trial," Clinical Oral Implants Research, vol. 21, no. 12, pp. 1345-1352, 2010.

[65] N. R. F. A. Silva, E. A. Bonfante, B. T. Rafferty et al., "Modified YTZP core design improves all-ceramic crown reliability," Journal of Dental Research, vol. 90, no. 1, pp. 104-108, 2011.

[66] Y. Kokubo, M. Tsumita, T. Kano, and S. Fukushima, "The influence of zirconia coping designs on the fracture load of allceramic molar crowns," Dental Materials Journal, vol. 30, no. 3, pp. 281-285, 2011.

[67] V. Preis, C. Letsch, G. Handel et al., "Influence of substructure design, veneer application technique, and firing regime on the in vitro performance of molar zirconia crowns," Dental Materials, vol. 29, no. 7, pp. 113-121, 2013. 
[68] A. Alhasanyah, T. K. Vaidyanathan, and R. J. Flinton, "Effect of core thickness differences on post-fatigue indentation fracture resistance of veneered zirconia crowns," Journal of Prosthodontics, vol. 22, no. 5, pp. 383-390, 2013.

[69] H. Q. Nguyen, K. B. Tan, and J. I. Nicholls, "Load fatigue performance of implant-ceramic abutment combinations," The International Journal of Oral \& Maxillofacial Implants, vol. 24, no. 4, pp. 636-646, 2009.

[70] B. Ohlmann, K. Marienburg, O. Gabbert, A. Hassel, H. Gilde, and P. Rammelsberg, "Fracture-load values of all-ceramic cantilevered fpds with different framework designs," International Journal of Prosthodontics, vol. 22, no. 1, pp. 49-52, 2009.

[71] Y. Zhang, J. J. Lee, R. Srikanth, and B. R. Lawn, "Edge chipping and flexural resistance of monolithic ceramics," Dental Materials, vol. 29, no. 12, pp. 1201-1208, 2013.

[72] J. H. Kim, S. J. Lee, J. S. Park, and J. J. Ryu, "Fracture load of monolithic CAD/CAM lithium disilicate ceramic crowns and veneered zirconia crowns as a posterior implant restoration," Implant Dentistry, vol. 22, no. 1, pp. 66-70, 2013.

[73] S. Rinke and C. Fischer, "Range of indications for translucent zirconia modifications: clinical and technical aspects," Quintessence International, vol. 44, no. 8, pp. 557-566, 2013.

[74] V. Preis, F. Weiser, G. Handel, and M. Rosentritt, "Wear performance of monolithic dental ceramics with different surface treatments," Quintessence International, vol. 44, no. 5, pp. 393405, 2013.

[75] W. Att, N. D. Yajima, M. Wolkewitz, S. Witkowski, and J. R. Strub, "Influence of Preparation and Wall Thickness on the Resistance to Fracture of Zirconia Implant Abutments," Clinical Implant Dentistry and Related Research, vol. 11, no. 1, pp. 196203, 2012.

[76] M. Hosseini, E. Kleven, and K. Gotfredsen, "Fracture mode during cyclic loading of implant-supported single-tooth restorations," The Journal of Prosthetic Dentistry, vol. 108, no. 2, pp. 7483, 2012.

[77] S. Rinke, S. Schafer, K. Lange et al., "Practice-based clinical evaluation of metal-ceramic and zirconia molar crowns: 3-year results," Journal of Oral Rehabilitation, vol. 40, no. 3, pp. 228237, 2013.

[78] P. Vigolo and S. Mutinelli, "Evaluation of zirconium-oxidebased ceramic single-unit posterior fixed dental prostheses (FDPs) generated with two CAD/CAM systems compared to porcelain-fused-to-metal single-unit posterior FDPs: a 5-year clinical prospective study," Journal of Prosthodontics, vol. 21, no. 4, pp. 265-269, 2012.

[79] I. Sailer, A. Zembic, R. E. Jung, C. H. F. Hämmerle, and A. Mattiola, "Single-tooth implant reconstructions: esthetic factors influencing the decision between titanium and zirconia abutments in anterior regions," The European Journal of Esthetic Dentistry, vol. 2, no. 3, pp. 296-310, 2007.

[80] I. Sailer, B. E. Pjetursson, M. Zwahlen, and C. H. F. Hämmerle, "A systematic review of the survival and complication rates of all-ceramic and metal-ceramic reconstructions after an observation period of at least 3 years-part II: fixed dental prostheses," Clinical Oral Implants Research, vol. 18, no. 3, pp. 86-96, 2007.

[81] B. E. Pjetursson, I. Sailer, M. Zwahlen, and C. H. F. Hämmerle, "A systematic review of the survival and complication rates of all-ceramic and metal-ceramic reconstructions after an observation period of at least 3 years-part I: single crowns," Clinical Oral Implants Research, vol. 18, no. 3, pp. 73-85, 2007.
[82] J. Abduo, K. Lyons, and M. Swain, "Fit of zirconia fixed partial denture: a systematic review," Journal of Oral Rehabilitation, vol. 37, no. 11, pp. 866-876, 2010.

[83] P. L. Tan, D. G. Gratton, A. M. Diaz-Arnold, and D. C. Holmes, "An in vitro comparison of vertical marginal gaps of CAD/CAM titanium and conventional cast restorations," Journal of Prosthodontics, vol. 17, no. 5, pp. 378-383, 2008.

[84] H. S. Han, H. S. Yang, H. P. Lim, and Y. J. Park, "Marginal accuracy and internal fit of machine-milled and cast titanium crowns," The Journal of Prosthetic Dentistry, vol. 106, no. 3, pp. 191-197, 2011.

[85] M. N. Aboushelib, W. A. Elmahy, and M. H. Ghazy, "Internal adaptation, marginal accuracy and microleakage of a pressable versus a machinable ceramic laminate veneers," Journal of Dentistry, vol. 40, pp. 670-677, 2012.

[86] G. Bornemann, S. Lemelson, and R. Luthardt, "Innovative method for the analysis of the internal 3D fitting accuracy of Cerec-3 crowns," International Journal of Computerized Dentistry, vol. 5, no. 2-3, pp. 177-182, 2002.

[87] J. Tinschert, G. Natt, S. Hassenpflug, and H. Spiekermann, "Status of current CAD/CAM technology in dental medicine," International Journal of Computerized Dentistry, vol. 7, no. 1, pp. 25-45, 2004.

[88] M. Tuntiprawon and P. R. Wilson, "The effect of cement thickness on the fracture strength of all-ceramic crowns," Australian Dental Journal, vol. 40, no. 1, pp. 17-21, 1995.

[89] R. W. Wassell, D. Barker, and J. G. Steele, "Crowns and other extra-coronal restorations: try-in and cementation of crowns," British Dental Journal, vol. 193, no. 1, pp. 17-20, 2002.

[90] M. Kikuchi and O. Okuno, "Machinability evaluation of titanium alloys," Dental Materials Journal, vol. 23, no. 1, pp. 37-45, 2004.

[91] E. O. Ezugwu, J. Bonney, and Y. Yamane, "An overview of the machinability of aeroengine alloys," Journal of Materials Processing Technology, vol. 134, no. 2, pp. 233-253, 2003.

[92] Z. Guimu, Y. Chao, S. R. Chen, and A. Libao, "Experimental study on the milling of thin parts of titanium alloy (TC4)," Journal of Materials Processing Technology, vol. 138, no. 1-3, pp. 489-493, 2003.

[93] E. Abele and B. Frohlich, "High speed milling of titanium alloys," Advances in Production Engineering \& Management, vol. 3, no. 3, pp. 131-140, 2008.

[94] Y. S. Terminasov and A. G. Yakhontov, "Distortion of lattice structure of metals by grinding," Metal Science and Heat Treatment of Metals, vol. 1, no. 5, pp. 19-23, 1959.

[95] B. Fransson, G. Øilo, and R. Gjeitanger, "The fit of metalceramic crowns, a clinical study," Dental Materials, vol. 1, no. 5, pp. 197-199, 1985.

[96] M. Molin and S. Karlsson, "A 3-year clinical follow-up study of a ceramic (Optec) inlay system," Acta Odontologica Scandinavica, vol. 54, no. 3, pp. 145-149, 1996.

[97] A. Bindl and W. H. Mörmann, "Fit of all-ceramic posterior fixed partial denture frameworks in vitro," International Journal of Periodontics and Restorative Dentistry, vol. 27, no. 6, pp. 567575, 2007.

[98] S. Reich, K. Kappe, H. Teschner, and J. Schmitt, "Clinical fit of four-unit zirconia posterior fixed dental prostheses," European Journal of Oral Sciences, vol. 116, no. 6, pp. 579-584, 2008.

[99] F. Beuer, H. Aggstaller, D. Edelhoff, W. Gernet, and J. Sorensen, "Marginal and internal fits of fixed dental prostheses zirconia retainers," Dental Materials, vol. 25, no. 1, pp. 94-102, 2009. 
[100] S. Witkowski, F. Komine, and T. Gerds, "Marginal accuracy of titanium copings fabricated by casting and CAD/CAM techniques," The Journal of Prosthetic Dentistry, vol. 96, no. 1, pp. 47-52, 2006.

[101] J. Abduo, "Fit of CAD/CAM implant frameworks: a comprehensive review," The Journal of Oral Implantology, 2012.

[102] J. Abduo, K. Lyons, V. Bennani, N. Waddell, and M. Swain, "Fit of screw-retained fixed implant frameworks fabricated by different methods: a systematic review," The International Journal of Prosthodontics, vol. 24, no. 3, pp. 207-220, 2011.

[103] B. Yüzügüllü and M. Avci, "The implant-abutment interface of alumina and zirconia abutments," Clinical Implant Dentistry and Related Research, vol. 10, no. 2, pp. 113-121, 2008.

[104] P. Vigolo, F. Fonzi, Z. Majzoub, and G. Cordioli, "An in vitro evaluation of titanium, zirconia, and alumina procera abutments with hexagonal connection," International Journal of Oral and Maxillofacial Implants, vol. 21, no. 4, pp. 575-580, 2006.

[105] M. Sierraalta, J. L. Vivas, M. E. Razzoog, and R. F. Wang, "Precision of fit of titanium and cast implant frameworks using a new matching formula," International Journal of Dentistry, vol. 2012, Article ID 374315, 9 pages, 2012.

[106] J. Abduo, K. Lyons, N. Waddell et al., "A comparison of fit of CNC-milled titanium and zirconia frameworks to implants," Clinical Implant Dentistry and Related Research, vol. 14, no. 1, pp. 20-29, 2012.

[107] T. Jemt, T. Bäck, and A. Petersson, "Precision of CNC-milled titanium frameworks for implant treatment in the edentulous jaw," International Journal of Prosthodontics, vol. 12, no. 3, pp. 209-215, 1999.

[108] M. Fernandez, L. Delgado, and M. Molmeneu, "Analysis of the misfit of dental implant-supported prostheses made with three manufacturing processes," The Journal of Prosthetic Dentistry, vol. 111, no. 2, pp. 116-123, 2013.

[109] P. A. Webb, "A review of rapid prototyping (RP) techniques in the medical and biomedical sector," Journal of Medical Engineering and Technology, vol. 24, no. 4, pp. 149-153, 2000.

[110] S. H. Choi and A. M. M. Chan, "A virtual prototyping system for rapid product development," Computer Aided Design, vol. 36, no. 5, pp. 401-412, 2004.

[111] S. H. Choi and H. H. Cheung, "A multi-material virtual prototyping system," Computer Aided Design, vol. 37, no. 1, pp. 123-136, 2005.

[112] Y. P. Kathuria, "Microstructuring by selective laser sintering of metallic powder," Surface and Coatings Technology, vol. 116-119, pp. 643-647, 1999.

[113] M. W. Khaing, J. Y. H. Fuh, and L. Lu, "Direct metal laser sintering for rapid tooling: processing and characterisation of EOS parts," Journal of Materials Processing Technology, vol. 113, no. 1-3, pp. 269-272, 2001.

[114] M. Salmi, K. S. Paloheimo, J. Tuomi et al., "A digital process for additive manufacturing of occlusal splints: a clinical pilot study," Journal of the Royal Society, Interface/the Royal Society, vol. 10, no. 84, pp. 1-6, 2013.

[115] C. C. Chang, M. Y. Lee, and S. H. Wang, "Digital denture manufacturing-an integrated technologies of abrasive computer tomography, CNC machining and rapid prototyping," International Journal of Advanced Manufacturing Technology, vol. 31, no. 1-2, pp. 41-49, 2006.

[116] Y. Bi, S. Wu, Y. Zhao, and S. Bai, "A new method for fabricating orbital prosthesis with a CAD/CAM negative mold," The Journal of Prosthetic Dentistry, vol. 110, no. 5, pp. 399-408, 2013.
[117] G. A. Mandelaris and A. L. Rosenfeld, "A novel approach to the antral sinus bone graft technique: the use of a prototype cutting guide for precise outlining of the lateral wall. A case report," International Journal of Periodontics and Restorative Dentistry, vol. 28, no. 6, pp. 569-575, 2008.

[118] M. Inokoshi, M. Kanazawa, and S. Minakuchi, "Evaluation of a complete denture trial method applying rapid prototyping," Dental Materials Journal, vol. 31, no. 1, pp. 40-46, 2012.

[119] N. R. F. A. Silva, L. Witek, P. G. Coelho, V. P. Thompson, E. D. Rekow, and J. Smay, "Additive CAD/CAM process for dental prostheses," Journal of Prosthodontics, vol. 20, no. 2, pp. 93-96, 2011.

[120] J. Ebert, E. Özkol, A. Zeichner et al., "Direct inkjet printing of dental prostheses made of zirconia," Journal of Dental Research, vol. 88, no. 7, pp. 673-676, 2009.

[121] T. Traini, C. Mangano, R. L. Sammons, F. Mangano, A. Macchi, and A. Piattelli, "Direct laser metal sintering as a new approach to fabrication of an isoelastic functionally graded material for manufacture of porous titanium dental implants," Dental Materials, vol. 24, no. 11, pp. 1525-1533, 2008.

[122] Y. Tang, H. T. Loh, Y. S. Wong, J. Y. H. Fuh, L. Lu, and X. Wang, "Direct laser sintering of a copper-based alloy for creating three-dimensional metal parts," Journal of Materials Processing Technology, vol. 140, no. 1-3, pp. 368-372, 2003.

[123] B. Vandenbroucke and J. P. Kruth, "Selective laser melting of biocompatible metals for rapid manufacturing of medical parts," Rapid Prototyping Journal, vol. 13, no. 4, pp. 196-203, 2007.

[124] L. M. de Vasconcellos, F. N. Oliveira, O. L. Dde et al., "Novel production method of porous surface Ti samples for biomedical application," Journal of Materials Science Materials in Medicine, vol. 23, no. 2, pp. 357-364, 2012.

[125] L. M. R. Vasconcellos, M. V. Oliveira, M. L. A. Graça, L. G. O. Vasconcellos, C. A. A. Cairo, and Y. R. Carvalho, "Design of dental implants, influence on the osteogenesis and fixation," Journal of Materials Science: Materials in Medicine, vol. 19, no. 8, pp. 2851-2857, 2008.

[126] E. Baril, L. P. Lefebvre, and S. A. Hacking, "Direct visualization and quantification of bone growth into porous titanium implants using micro computed tomography," Journal of Materials Science: Materials in Medicine, vol. 22, no. 5, pp. 1321-1332, 2011.

[127] M. A. Tara, S. Eschbach, F. Bohlsen, and M. Kern, "Clinical outcome of metal-ceramic crowns fabricated with laser-sintering technology," The International Journal of Prosthodontics, vol. 24, no. 1, pp. 46-48, 2011.

[128] M. Wu, J. Tinschert, M. Augthun et al., "Application of laser measuring, numerical simulation and rapid prototyping to titanium dental castings," Dental Materials, vol. 17, no. 2, pp. 102-108, 2001.

[129] E. Özkol, J. Ebert, K. Uibel, A. M. Wätjen, and R. Telle, "Development of high solid content aqueous 3 Y-TZP suspensions for direct inkjet printing using a thermal inkjet printer," Journal of the European Ceramic Society, vol. 29, no. 3, pp. 403-409, 2009.

[130] X. Zhao, J. R. G. Evans, M. J. Edirisinghe, and J. H. Song, "Direct ink-jet printing of vertical walls," Journal of the American Ceramic Society, vol. 85, no. 8, pp. 2113-2115, 2002.

[131] G. Wu, B. Zhou, Y. Bi, and Y. Zhao, "Selective laser sintering technology for customized fabrication of facial prostheses," The Journal of Prosthetic Dentistry, vol. 100, no. 1, pp. 56-60, 2008.

[132] J. Wu, B. Gao, H. Tan, J. Chen, C.-Y. Tang, and C.-P. Tsui, “A feasibility study on laser rapid forming of a complete titanium 
denture base plate," Lasers in Medical Science, vol. 25, no. 3, pp. 309-315, 2010.

[133] K. Quante, K. Ludwig, and M. Kern, "Marginal and internal fit of metal-ceramic crowns fabricated with a new laser melting technology," Dental Materials, vol. 24, no. 10, pp. 1311-1315, 2008.

[134] Y. Ucar, T. Akova, M. S. Akyil, and W. A. Brantley, "Internal fit evaluation of crowns prepared using a new dental crown fabrication technique: laser-sintered Co-Cr crowns," The Journal of Prosthetic Dentistry, vol. 102, no. 4, pp. 253-259, 2009.

[135] R. Castillo-Oyague, C. D. Lynch, A. S. Turrion et al., "Misfit and microleakage of implant-supported crown copings obtained by laser sintering and casting techniques, luted with glass-ionomer, resin cements and acrylic/urethane-based agents," Journal of Dentistry, vol. 41, no. 1, pp. 90-96, 2013.

[136] R. J. Williams, R. Bibb, and D. Eggbeer, "CAD/CAM-fabricated removable partial-denture alloy frameworks," Practical Procedures \& Aesthetic Dentistry, vol. 20, no. 6, pp. 349-351, 2008.

[137] X. Yan and P. Gu, "A review of rapid prototyping technologies and systems," Computer Aided Design, vol. 28, no. 4, pp. 307-318, 1996.

[138] M. M. Soares, N. D. Harari, E. S. Cardoso et al., "An in vitro model to evaluate the accuracy of guided surgery systems," The International Journal of Oral \& Maxillofacial Implants, vol. 27, no. 4, pp. 824-831, 2012.

[139] W. J. van der Meer, A. Vissink, G. M. Raghoebar, and A. Visser, "Digitally designed surgical guides for placing extraoral implants in the mastoid area," The International Journal of Oral \& Maxillofacial Implants, vol. 27, no. 3, pp. 703-707, 2012.

[140] C. M. Cheah, C. K. Chua, and K. H. Tan, "Integration of laser surface digitizing with CAD/CAM techniques for developing facial prostheses-part 2: development of molding techniques for casting prosthetic parts," International Journal of Prosthodontics, vol. 16, no. 5, pp. 543-548, 2003. 


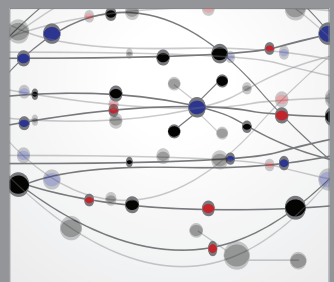

The Scientific World Journal
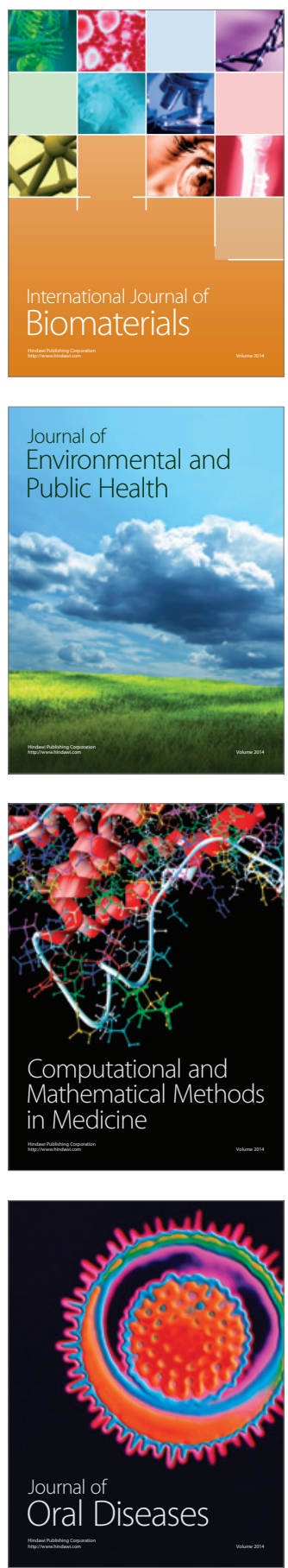
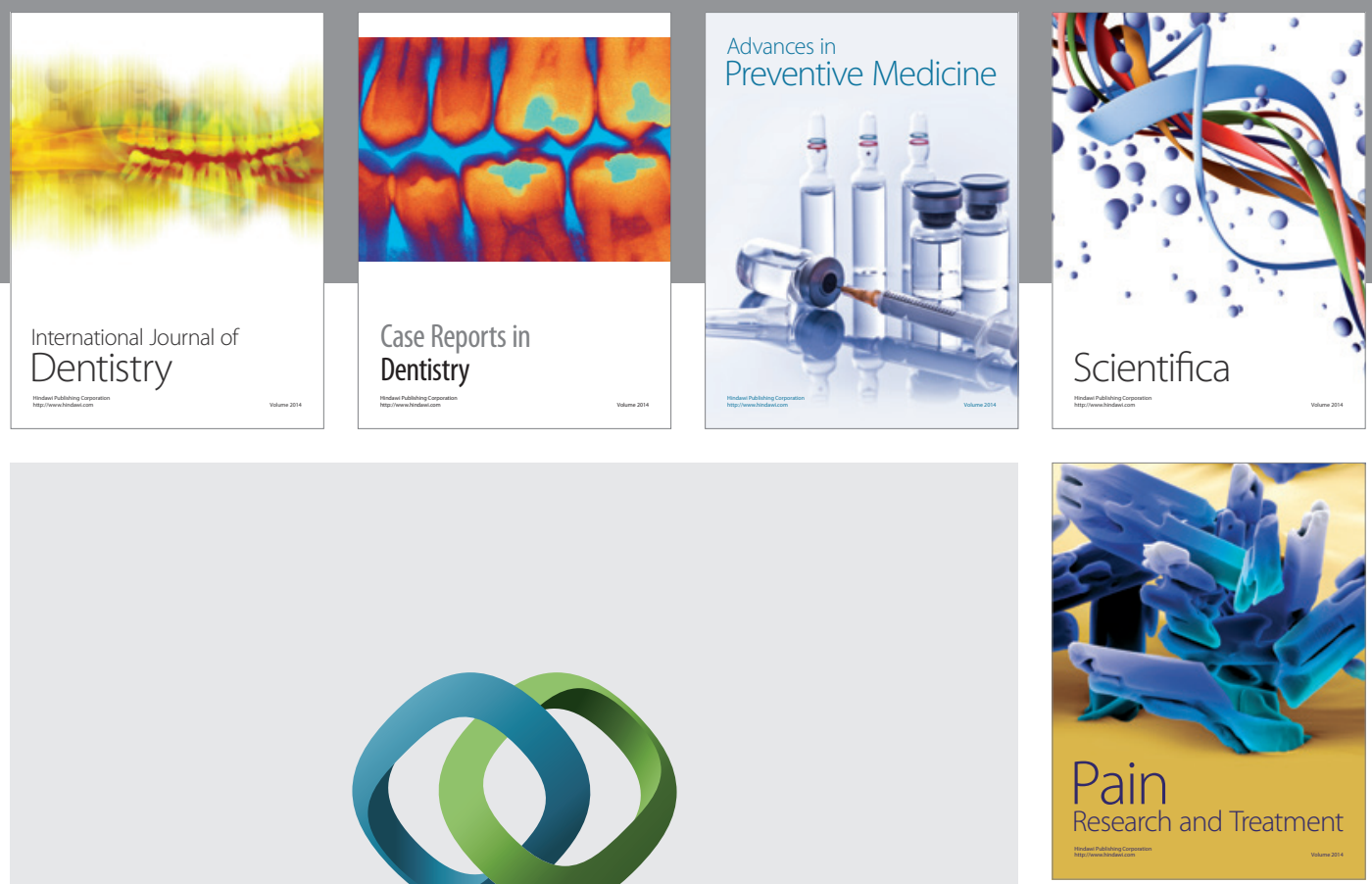

\section{Hindawi}

Submit your manuscripts at

http://www.hindawi.com
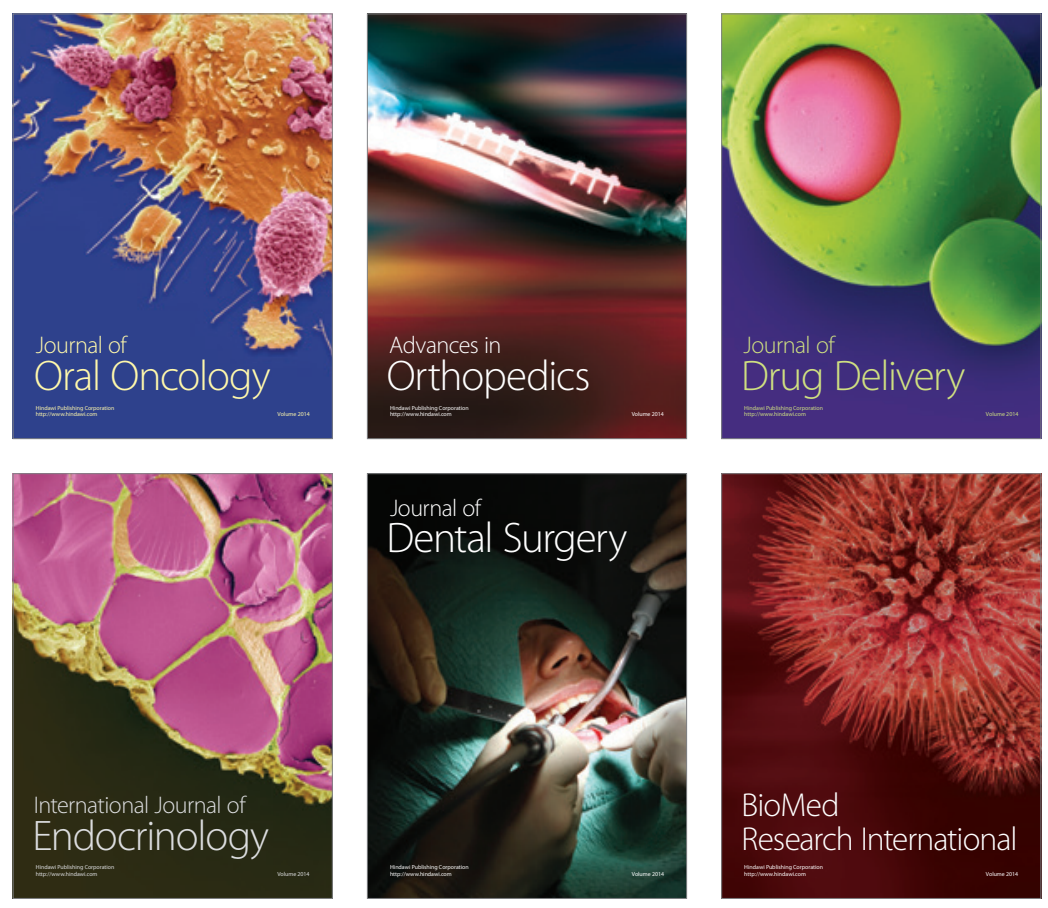

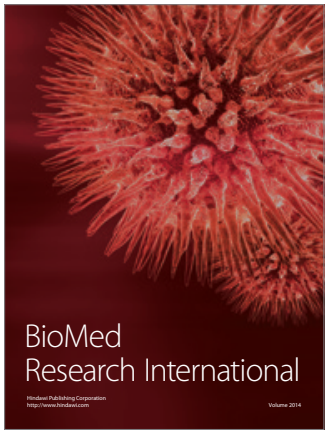

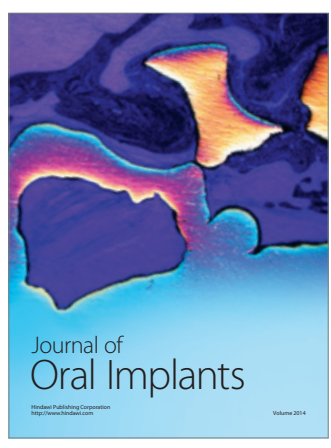
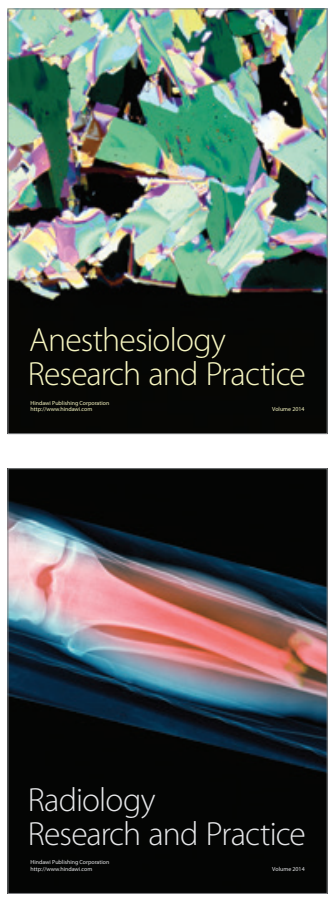